\title{
The Gastroesophageal Disease and Its Association to Ear, Nose, Throat Complaints
}

\author{
Habib Merza1, Hanan Abdulkhaleq² \\ ${ }^{1}$ ENT, Head \& Neck Surgery Department, Salmaniya Medical Complex, Ministry of Health, Manama, Kingdom of Bahrain \\ ${ }^{2}$ Peadiatrtic Department, Salmaniya Medical Complex, Ministry of Health, Manama, Kingdom of Bahrain \\ Email: drhabibmerza@yahoo.com
}

How to cite this paper: Merza, H. and Abdulkhaleq, H. (2021) The Gastroesophageal Disease and Its Association to Ear, Nose, Throat Complaints. International Journal of Otolaryngology and Head \& Neck Surgery, 10, 337-344.

https://doi.org/10.4236/ijohns.2021.105030

Received: July 3, 2021

Accepted: August 2, 2021

Published: August 5, 2021

Copyright (c) 2021 by author(s) and Scientific Research Publishing Inc. This work is licensed under the Creative Commons Attribution International License (CC BY 4.0).

http://creativecommons.org/licenses/by/4.0/

\section{Open Access}

\begin{abstract}
Objectives: In many articles, gastroesophageal reflux has been identified as a strong underlying factor in laryngeal and extra-laryngeal disorders. But the exact mechanism of these complications is still controversial. The present study was designed to investigate the association of gastroesophageal acid reflux to ear, nose and throat diseases in children. Materials and Methods: The present study is a descriptive cross-sectional study and its statistical population includes children with gastroesophageal reflux disease over a period of 18 months visited Salmaniya Medical Complex, Kingdom of Bahrain. The diagnosis of GERD (Gastroesophageal reflux disease) was recorded based on symptoms, radiological and endoscopic findings and ESPGHAN guidelines. The ear, nose and throat were examined and problems recorded followed by initiation of medical treatment. After one and six months of follow up post treatment all clinical findings were recorded. Results: $26.4 \%$ of the children were under one year old. In $78 \%$ of children, a family history of GERD was reported to be negative. Cough was the most common clinical complaint. After one month of treatment, $15 \%$ of gastrointestinal symptoms and $40 \%$ of ENT symptoms completely improved. After six months of treatment $72 \%$ percentage of gastrointestinal symptoms and ENT symptoms completely improved. Conclusion: This study showed that gastroesophageal reflux disease should be considered, diagnosed and treated in all children with refractory ear, nose and throat symptoms.
\end{abstract}

\section{Keywords}

Children, Ear, Nose, Throat, Gastroesophegeal Reflux Disease

\section{Introduction}

Gastroesophageal reflux is retrograde movement of gastric contents into the 
esophagus that occurs primarily after meals and is a normal physiologic process that prevents excessive gastric distension and dyspepsia. Gastroesophageal reflux disease (GERD) is defined as an abnormally elevated frequency of gastric reflux and/or volume of gastric refluxate, and typically presents as troublesome symptoms including heartburn and regurgitation. Gastroesophageal reflux disease (GERD) is one of the most common gastrointestinal diseases, especially in childhood, which is characterized by esophageal and extra-esophageal manifestations [1] [2]. Numerous studies have shown the relationship between gastroesophageal reflux disease (GERD) and diseases of the ears, nose and throat particularly, in children [3]. Clinical manifestations of ENT diseases in the context of GERD are called atypical manifestations. In general, the symptoms of gastroesophageal reflux disease can be described in two ways. Gastrointestinal symptoms (nausea, vomiting, difficulty swallowing, gagging and growth disorder in pediatric and extra-esophageal or non-gastrointestinal symptoms (chronic cough, wheezing, hoarseness, sore throat, stridor, recurrent croup, and obstructive sleep apnea). All of the above manifestations are due to the untimely relaxation of the lower esophageal sphincter and the uncoordinated movement of the esophagus, which leads to reflux of stomach contents into the esophagus. Delay in emptying the stomach and increasing its acidity can also cause and exacerbate reflux [4].

Among the extra-esophageal symptoms, the most common complaints are airway obstruction and laryngeal reflux effects, often manifested in the form of cough and hoarseness. Infants who reflex back the contents of their stomach, as long as they feed and grow enough and do not suffer from respiratory symptoms or gastrointestinal complications, they are considered as physiological reflux [5] [6].

Screening is important in patients who have experienced silent GERD with respiratory symptoms, as this condition can lead to a wide range of complications. Although GERD is common in childhood, other causes of chronic airway inflammation should not be overlooked. The most common complication of laryngeal reflux in children is recurrent subglottic laryngitis with dyspnea (croup). Gastric acid reflux that affects the nasopharynx can lead to edema in that area and eventually to middle ear disease.

Although the 24-hour esophageal $\mathrm{pH}$ test cannot be routinely used in the pediatric age group, it is still the gold standard of diagnosis of gastric acid reflux into the esophagus [6].

A pH below 4 allows the doctor to start treatment, although a negative test does not rule out gastroesophageal reflux disease [7].

Considering that gastroesophageal reflux disease is a common diagnosis in children, which can lead to sever damage in a person's life, this study investigates the relationship between GERD and manifestations of diseases of the ear, nose and throat.

The present study is a descriptive cross-sectional study and its statistical population includes children with gastroesophageal reflux disease visited Salmaniya Medical Complex during eighteen months. 


\section{Materials \& Methods}

Thirty eight children aged six months to six years were studied over eighteen months period (October 2018-March 2020). Diagnosis of GERD was recorded based on signs \& symptoms with radiological and endoscopic findings and ESPGHAN guidelines [7] [8]. All patients with syndromic or metabolic diseases were excluded from the study.

All patients were examined for ENT symptoms by consultant ear, nose and throat surgeon before starting treatment and patients' clinical and laboratory findings were entered into a questionnaire designed for this study, followed by initiation of the GERD treatment by consultant pediatric gastroenterologist and ear, nose, throat problems by consultant ENT surgeon.

One and six months after treatment, the ears, throat and nose were examined again and the results were compared. Demographic variables and gastrointestinal symptoms, ear, nose and throat symptoms, medications used to treat patients, improvement from gastrointestinal symptoms and ear, nose and throat symptoms were collected one and six months after treatment.

The above data are recorded and the information obtained analyzed using ver.26 SPSS statistical analyzing software.

\section{Results}

In this study during eighteen months, thirty eight children aged six months to six years (18 females and 20 males) with gastroesophageal reflux disease were evaluated for ear, nose and throat complications. $26.4 \%$ of the children were under one year old (Table 1).

The lowest weight was reported $6 \mathrm{~kg}$ and the maximum $27 \mathrm{~kg}$ with an average weight of $11 \mathrm{~kg}$. In $78 \%$ of children, a family history of GERD was reported negative. In $12 \%$ of patients with a positive family history of GERD, $5.5 \%$ was reported in father, $3 \%$ was reported in mother and 3.5\% was reported in sibling.

Cough, snoring at night, sore throat and purulent discharge from the nose with $47.3 \%, 42 \%, 31.2 \%$, and $18.4 \%$ were the most common clinical complaints respectively (Tables $2-4$ ).

In $70 \%$ of cases ranitidine, in $47.5 \%$ of cases metoclopramide, in $32.5 \%$ of cases omeprazole and in $38.5 \%$ of cases domperidone were used for treatment. One month after treatment: $80 \%$ of gastrointestinal symptoms and $52.5 \%$ of ENT symptoms had a relative improvement. $15 \%$ of gastrointestinal symptoms and $40 \%$ of ENT symptoms were completely cured. $5 \%$ of gastrointestinal symptoms and $7.5 \%$ of ENT symptoms did not improve.

Six months after treatment $1 \%$ of gastrointestinal symptoms and 3\% of ENT symptoms had not yet improved. $35.13 \%$ of gastrointestinal symptoms and $27 \%$ of ENT symptoms had relative improvement. $72 \%$ of gastrointestinal symptoms and $70 \%$ of ENT symptoms completely recovered. Among these 38 cases, two cases had cerebral palsy which no significant association was found between the underlying disease and symptoms, and the response to drug therapy was successful. 
Table 1. Patients' age distribution.

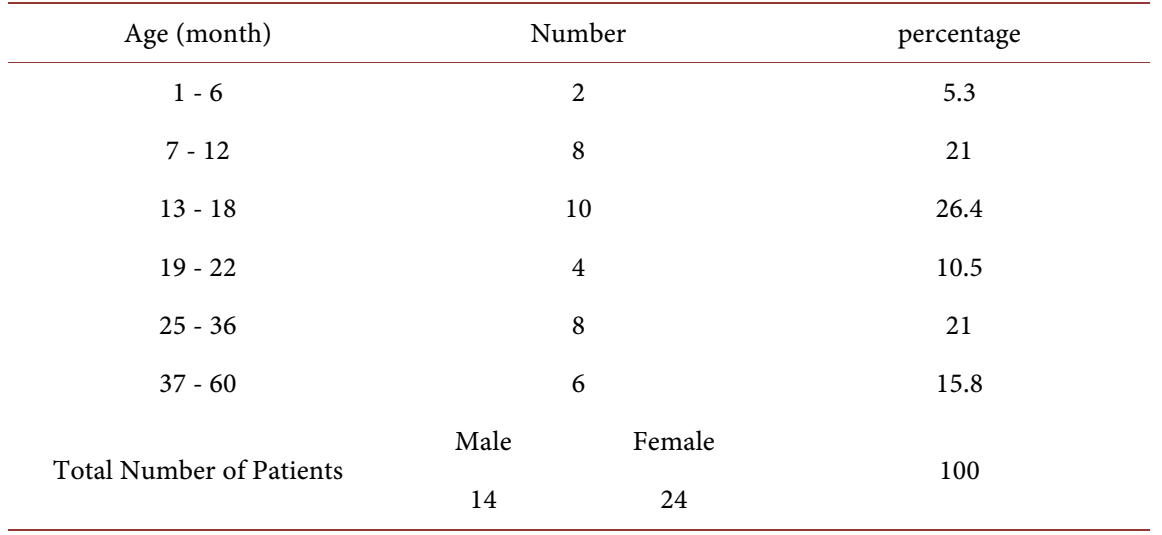

Table 2. Frequency of symptoms related to GERD.

\begin{tabular}{ccc}
\hline symptoms & Number & Percentage \\
\hline Heartburn & 2 & 5.3 \\
Regurgitation & 7 & 18.4 \\
vomiting & 30 & 79 \\
dysphagia & 5 & 10.5 \\
cough & 18 & 47.3 \\
Chest pain & 0 & 0 \\
Apnea attack & 3 & 7.9 \\
Weight loss & 5 & 13.2 \\
GI bleeding & 0 & 0 \\
Loss of appetite & 12 & 32 \\
Exacerbation of the symptoms with oral intake & 3 & 7.9 \\
\hline
\end{tabular}

Table 3. Frequency of the patients' complaint.

\begin{tabular}{ccc}
\hline Type of complaint & Number & Percentage \\
\hline Nose block & 6 & 15.8 \\
Nose purulent discharge & 7 & 18.4 \\
Nose bloody discharge & 2 & 5.2 \\
Acute sore throat & 12 & 31.2 \\
Chronic sore throat & 7 & 18.4 \\
Cough & 25 & 65.8 \\
Hoarseness & 4 & 10.5 \\
Facial pain & 2 & 5.2 \\
Headache & 1 & 2.6 \\
Fatigue & 0 & 0 \\
Snoring & 16 & 42 \\
Mouth breathing & 6 & 15.8
\end{tabular}


Table 4. Frequency of findings in patients' examination.

\begin{tabular}{ccc}
\hline Type of finding & Number & Percentage \\
\hline Adenoid enlargement & 13 & 34 \\
Tonsil enlargement & 20 & 53 \\
Chronic tonsillitis & 8 & 21 \\
Laryngitis & 6 & 16 \\
Pain over sinuses region & 2 & 5.2 \\
Acute otitis media & 11 & 29 \\
Chronic otitis media & 1 & 2.6 \\
Hypertrophy inferior turbinate & 2 & 5.2 \\
Dental Cares & 6 & 16 \\
\hline
\end{tabular}

\section{Discussion}

In many articles, gastroesophageal reflux has been identified as a strong factor in laryngeal and supralaryngeal disorders. Although the link between gastric acid reflux to the esophagus and pathologies of the ear, throat and nose is known, the exact mechanism of these pathologies is still questionable [9] [10].

Heavner et al. from the University of Carolina Hospital in the United States found GERD to be a common finding in preterm infants and children and a contributing factor to transient inflammation and Eustachian tube dysfunction [10]. Junqueira et al. (2007) from the Federal University of Rio de Janeiro in Brazil surveyed 38 children aged 14 to 16 months in 2007 and found a significant effect of GERD on ear, nose and throat diseases and respiratory diseases including asthma [11].

In the present study, 38 children with gastroesophageal reflux disease, whose diagnosis was confirmed by upper gastrointestinal studies or ultrasound or endoscopy, were examined for complications of ear, throat and nose, the most common complaint was the cough in 18 cases $(47.3 \%)$ and the most common finding was the enlargement of the tonsils, which was observed in 20 cases (53\%), while only in one of the patient (2.6\%) otitis media was observed. In a study by Megale et al. (2006) in relation to the complications of GERD, chronic cough was the most common complaint (96.68\%) of the cases which consistent with our study, and the common finding of the examination in the study was middle ear infection in $100 \%$ of cases, which contradicted our findings in the examination (Table 4) [12]. In the study of Bouchard S. (2007) most extra-esophageal complications of GERD included dysphonia, increased saliva, laryngospasm, and nocturnal apnea attacks, and symptoms of ear, throat, and nose symptoms were persistent cough, earache, and painful swallowing [13].

In the present study, patients were treated for one month with acid inhibitor and prokinetic. One month after starting treatment $40 \%$ of ear, nose and throat symptoms are completely cured, $52.5 \%$ has a relative improvement and $7.5 \%$ of patients did not recover. In the case of gastrointestinal symptoms, $15 \%$ were 
complete, $80 \%$ were partial, and 5\% were not. With continued treatment after 6 months, $1 \%$ of gastrointestinal symptoms and $3 \%$ of ENT symptoms remained.

In the study by Bouchard et al., patients with GERD were treated with antacids and prokinetics for 8 weeks, which was successful in improving ear, nose and throat symptoms [13].

Megale et al. In a study of 45 children aged 3 months to 12 years with GERD showed that resistant serous otitis media could be treated with concomitant GERD treatment [12]. In the study of Wong et al., Laryngitis was a common complication due to reflux and it has been shown that reflux can be considered as a factor for causing multiple simultaneous complications in the upper respiratory tract [14].

Halstea et al. were able to reduce the need for subglottic stenosis surgery by $35 \%$ with aggressive GERD drug therapy [15].

Bothwell et al. showed that aggressive drug treatment of GERD in children with chronic sinusitis prevents sinus surgery in most of the patients [16].

Basically, rhinosinusitis and serous otitis media are considered the main manifestations of GERD and although the exact mechanism of rhinosinusitis due to reflux is not known, but as a cause of resistance in the usual treatment of pediatric sinusitis should be considered [16] [17] [18].

Due to the fact that gastroesophageal reflux is often overlooked and since it plays an important role in causing many complications of the ear, nose and throat, it is necessary to be very careful and sensitive in diagnosing and treating this disease.

In most cases, the basis of treatment in the age group of children is medical treatment which with early diagnosis and early treatment, we can expect a proper response as in the present study, in the vast majority of patients, with timely initiation of treatment and follow-up within one month and six months later, the main gastrointestinal and ear, nose and throat symptoms disappeared and had a positive effect on their lives and activities.

\section{Conclusion}

According to the appropriate therapeutic response in the results of the present study, it can be concluded that with early diagnosis and treatment of GERD in the young age group, we can prevent the ear, nose and throat manifestations related to GERD and improve the lifestyle and function of many children. On the other hand, the need to evaluate GERD in children with chronic or refractory upper respiratory tract diseases can be emphasized.

\section{Conflicts of Interest}

The authors declare no conflicts of interest regarding the publication of this paper.

\section{References}

[1] Vinay, C., et al. (2019) Clinical Gastrointestinal Endoscopy. 3rd Edition, Elsevier, Amsterdam, 268-278. 
[2] Orenstein, S., Peters, J. and Khan, S. (2020) Gastroesophageal Reflux Disease (GERD). In: Kliegman, R.M., Behrman, R.E., Jenson, H.B., Stanton, B.F., Eds., Nelson Textbook of Pediatrics, 21th Edition, Chapter 315, Saunders Elsevier, Philadelphiap, 12661270.

[3] Cummings, C.W., Haughey, H., Regan, T., Harker, L. and Flint, P. (2020) Cummings Otolaryngology: Head and Neck Surgery. 7th Edition, Elsevier Mosby Publisher, 4286-4289.

[4] Deschener, W.K. and Benjamin, S.B. (1989) Extraesophageal Manifestation of Gastroesophageal Reflux. The American Journal of Gastroenterology, 84, 1-5.

[5] Ahuja, V., Yencha, M.W. and Lassen, L.F. (1999) Head and Neck Manifestations of Gastroesophageal Reflux Disease. American Family Physician, 60, 873-880, 885-886.

[6] Suskind, D.L., Zeringue, G.P. and Kluka, E.A. (2001) Gastroesophageal Reflux and Pediatric Otolaryngologic Disease. Archives of Otolaryngology: Head and Neck Surgery, 127, 511-514. https://doi.org/10.1001/archotol.127.5.511

[7] Vandenplas, Y., Rudolph, C.D., Di Lorenzo, C., Hassall, E., Liptak, G., Mazur, L., et al. (2009) North American Society for Pediatric Gastroenterology Hepatology and Nutrition, European Society for Pediatric Gastroenterology Hepatology and Nutrition. Journal of Pediatric Gastroenterology and Nutrition, 49, 498-547. https://doi.org/10.1097/MPG.0b013e3181b7f563

[8] Katz, P., Gerson, L. and Vela, M. (2013) Guidelines for the Diagnosis and Management of Gastroesophageal Reflux Disease. The American Journal of Gastroenterology, 108, 308-328. https://doi.org/10.1038/ajg.2012.444

[9] Wenzl, T.G., Moroder, C., Trachterna, M., Thomson, M., Silny, J., Heimann, G., et al. (2002) Esophageal pH Monitoring and Impedance Measurement: A Comparison of Two Diagnostic Tests for Gastroesophageal Reflux. Journal of Pediatric Gastroenterology and Nutrition, 34, 519-523. https://doi.org/10.1097/00005176-200205000-00009

[10] Heavner, S.B., Hardy, S.M., White, D.R. and Prazma, J. (2001) Pillsbury HC 3rd Transient Inflammation and Dysfunction of the Eustachian Tube Secondary to Multiple Exposures of Simulated Gastroesophageal Refluxant. Annals of Otology, Rhinology \& Laryngology, 110, 928-934. https://doi.org/10.1177/000348940111001007

[11] Junqueira, J.C. and Penna, F.J. (2007) Nasopharyngeal pH and Gastroesophgeal Reflux in Children with Chronic Respiratory Disease. Journal de Pediatric, 83, 225232. https://doi.org/10.2223/JPED.1634

[12] Megale, S.R., Scanavin, A.B. and Andrade, E.C. (2006) Gastroesophageal Reflux Disease, It's Importance in Ear, Nose and Throat. International Journal of Pediatric Otorhinolaryngology, 70, 80-81. https://doi.org/10.1016/j.ijporl.2005.05.021

[13] Bouchard, S., Lallier, M., Yazbeck, S. and Bensoussan, A. (1999) The Otolaryngology Manifestations of Gastroesophageal Reflux: When Is a pH Study Indicated? Journal of Pediatric Surgery, 34, 1053-1056. https://doi.org/10.1016/S0022-3468(99)90562-6

[14] Wong, R.K., Hanson, D.G., Waring, P.J. and Shaw, G. (2000) ENT Manifestations of Gastroesophageal Reflux. The American Journal of Gastroenterology, 95, 15-22. https://doi.org/10.1016/S0002-9270(00)01074-1

[15] Halstead, L.A. (1999) Gastroesophageal Reflux: A Critical Factor in Pediatric Subgolttic Stenosis. Otolaryngology-Head and Neck Surgery, 120, 683-688.

https://doi.org/10.1053/hn.1999.v120.a91766

[16] Bothwell, M.R., Parsons, D.S., Talbot, A., Barbero, G.J. and Wilder, B. (1999) Outcome of Reflux Thrapy in Pediatric Chronic Sinusitis. Otolaryngology-Head and Neck Surgery, 121, 255-262. https://doi.org/10.1016/S0194-5998(99)70181-6 
[17] Phipps, C.D., Wood, W.E., Gibson, W.S. and Cochran, W.J. (2000) Gastroesophageal Reflux Contributing to Chronic Sinus Disease in Children: A Prospective Analysis. Archives of Otorhinolaryngology: Head \& Neck Surgery, 126, 831-836. https://doi.org/10.1001/archotol.126.7.831

[18] Caruso, G. and Passali, F.M. (2006) ENT Manifestations of Gastrooesophageal Reflux in Children. ACTA Otorhinolaryngologica Italica, 26, 252-255. 